Journal of Environmental Assessment Policy and Management

Vol. 16, No. 3 (September 2014) 1450028 (28 pages)

Imperial College Press

(C) The Authors

DOI: $10.1142 / S 1464333214500288$

\title{
POLICY INTEGRATION OF ENVIRONMENTAL ASSESSMENT AND DISASTER MANAGEMENT
}

\author{
RYO TAJIMA* \\ National Institute for Environmental Studies \\ 16-2 Onogawa, Tsukuba \\ Ibaraki, 305-8506, Japan \\ tajima.ryo@nies.go.jp \\ TOM GORE and THOMAS B. FISCHER \\ School of Environmental Sciences \\ University of Liverpool \\ 74 Bedford Street South \\ Liverpool L69 7ZQ, UK \\ Received 31 March 2014 \\ Revised 11 July 2014 \\ Accepted 26 July 2014 \\ Published 7 October 2014
}

\begin{abstract}
This paper aims to clarify the potential benefits and challenges of integrating environmental assessment (EA) and disaster management considerations, and current research gaps. In this context, the discussion is provided from three perspectives: (1) the consideration of disaster risk in EA; (2) the development of accelerated EA for post-disaster situations; and (3) the integration of EA into pre-disaster response and recovery planning. For this, a Japanese JSPS (Japan Society for the Promotion of Science)/UK ESRC (Economic and Social Research Council) financed UK-Japan project on the integration of environmental assessment (EA) and disaster management was conducted in 2012. It was concluded that whilst EA can be beneficial for disaster management, there are a number of potential pitfalls and an evident lack of research in the area.
\end{abstract}

Keywords: Environmental degradation; environmental assessment; disaster management; disaster risk reduction; integration.

${ }^{*}$ Corresponding author. 


\section{Introduction}

Within the context of emerging disaster risks, especially those related to climate (Smith, 2013), disaster management is now seen to play an important role in sustainable development. For example, the Japanese Ministry of Environment added "safety and secure society" in their definition of "sustainable society" against the backdrop of 2011 Tōhoku Earthquake and Fukushima nuclear power station incident (Ministry of the Environment, Japan, 2012). One instrument that has gained attention within the context of disaster management has been environmental assessment (EA), a well-established environmental management tool which acts in an ex-ante manner to promote the consideration of environmental issues in human development actions (Fischer et al., 2008). Potential benefits of EA in disaster management have been recognised by many organisations (see e.g. Randall and Jowett, 2010). However, to date, how EA is to be integrated with disaster management has not been well established. There is great potential and need for the instrument, though, at a time when tackling disaster risk factors at the root is widely perceived to be the area of slowest progress under the Hyogo Framework for Action (UNISDR, 2011).

This paper aims to set a milestone towards the enhancement of research on the integration of EA and disaster management. In accordance with this, three potential means of integration are identified, drawing on theories of disaster management and EA. These three areas reflect closely the aspirations set out in the Hyogo Framework and concern the application of EA in both an on-going developmental context and in the aftermath of disaster events. They serve as the basic framework for the discussion conducted throughout the paper. The current research status will then be established through a comprehensive literature survey. Finally, drawing on the outcomes of the UK ESRC (Economic and Social Research Council) and Japanese JSPS (Japan Society for the Promotion of Science) funded workshop engaging UK and Japan based EA and disaster management researchers and practitioners held in Tokyo in November/December 2012 (the Tokyo workshop, hereinafter), ${ }^{1}$ the three potential means for integration will be further explored and prospects for further research presented.

\footnotetext{
${ }^{1}$ The results of the Tokyo workshop are presented in Gore et al. (2012). Initial findings are discussed in Gore et al. (2013). For the workshop programme, see http://www.nishikiz.depe.titech.ac.jp/pdfs/ 2012JSPS_Final\%20Program.pdf.
} 


\section{Rationale and Opportunities for Integrating EA and Disaster Management}

\section{The rationale for EA and disaster management integration}

The relationship between development and disaster, or disaster and the environment, has been discussed by various researchers (e.g. Collins, 2009; Shaw, 2006; Srinivas and Nakagawa, 2008). Compiling the findings of existing work, Gore and Fischer (2014) illustrated the interrelationship between human action, environmental degradation, and disaster events, as shown in Fig. 1. Here human development actions, ranging from abstract policy making to concrete projects, are shown to have the potential to lead to environmental degradation. Environmental degradation is shown to affect the risk of disaster events through its impact on hazards and vulnerabilities. Disaster events, in turn, when they occur, are shown to be a potential source of additional environmental damage through the action of the disaster agent and the impact of the event on human development actions. Here, we can see the means-ends relationship between environmental consideration through EA and disaster management; while the prevention of environmental degradation by human development action is the ends of EA, this can also be a means for disaster management as environmental degradation is a key driver of disaster risk. This is where the basic rationale for integrating EA and disaster management lies.

The main focus of this paper is on disasters related to natural hazards (e.g. earthquakes) or quasi-natural hazards (e.g. flooding). Technical or industrial hazards (e.g. chemical plant accident) relate more to risk governance perspective and will not be covered.

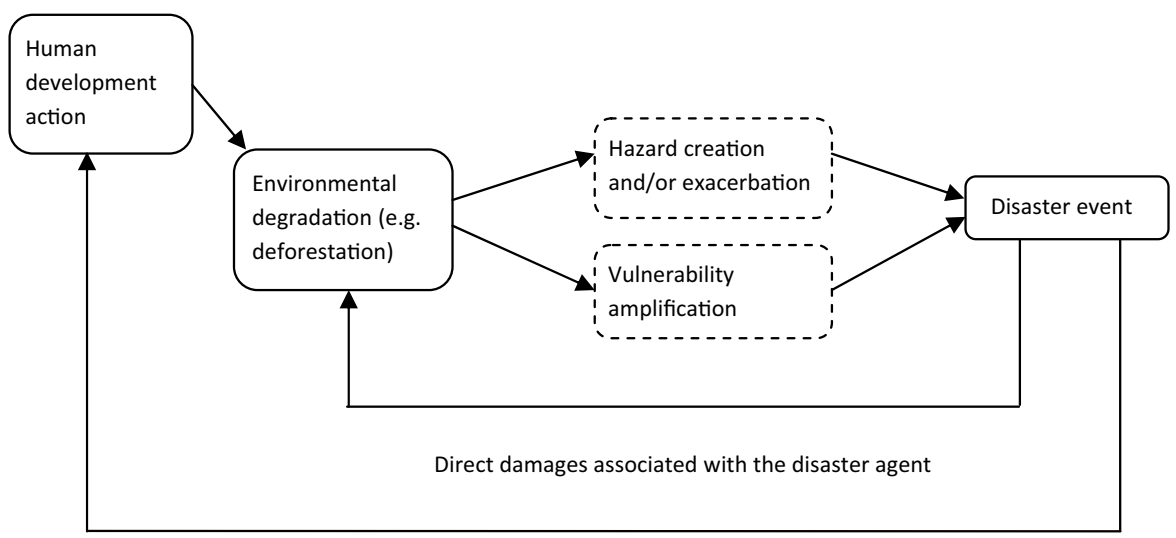

Indirect damages (e.g. poverty)

Fig. 1. Linkages between development, environment and disaster (Gore and Fischer, 2014). 


\section{Human activities related to disaster management}

Disaster management is frequently presented in terms of a number of actions. These typically consist of mitigation, preparedness, response and recovery. These are often depicted in the form of a cycle with the first two activities shown to occur sequentially prior to disaster, and the latter two sequentially afterwards (e.g. Alexander, 2002). This representation is, however, obviously simplistic and activities can be seen to overlap and occur concurrently, particularly depending on the use of the terminology.

\section{Pre-disaster activities}

In the pre-disaster period (i.e. during the on-going development process) efforts are undertaken to mitigate and prepare for disasters. Mitigation activities involve the utilisation of a wide array of measures, often classified as structural and nonstructural, to reduce risk including, for example, land-use planning, building codes and engineered structures (e.g. dams and levees) (Mileti, 1999). Preparedness activities, on the other hand, involve the development of capacities to respond to and recover from a disaster event, recognising that despite the best efforts there will always be some degree of risk. This includes activities such as training responders, stockpiling important resources, planning and exercising these plans.

Pre-disaster planning is a central pre-event activity. Planning activities can be hazard specific or, as has been more recently advocated, generic/"all hazards" in nature and can encompass both response and recovery processes (Quarantelli, 1997; Perry and Lindell, 2003). Planning for response typically involves activities such as determining evacuation arrangements and the identification of facilities for functions, including immediate sheltering, reception centres for friends and relatives and temporary mortuaries. These facilities are normally pre-existing structures considered to be invulnerable to the anticipated disaster agent giving rise to the situation and suitably accessible. It also commonly involves delineating the roles and responsibilities of key agencies and an overall coordinating structure to support the response effort. Accordingly, an inter-organisational approach to planning is often advocated (Perry and Lindell, 2003; Heide, 2005). Pre-disaster planning for recovery, in contrast, generally includes defining overarching policies and objectives to guide the recovery effort, identifying potential sources of financial assistance and determining sites for certain post-disaster functions such as accommodation. Like response planning, it also usually involves defining the roles and responsibilities of various actors and a coordinating structure which, in a recovery context, often includes the establishment of a specialist agency. Community involvement is frequently advocated as a key principle of the pre-disaster 
recovery planning process (IRP, 2012). Such planning is seen as presenting an important opportunity for ensuring the involvement of the public in recovery issues, something considered critical to its effectiveness.

Notably, recovery planning is far less common globally than response planning. Recovery efforts are instead usually guided by plans and approaches devised reactively in the post-disaster period. This situation has been attributed to a lack of resources and political will (Alexander, 2002). Pre-disaster recovery planning is, in particular vulnerable to criticism that necessitated resources would be better deployed in preventing the occurrence of the situation in the first place (Nakabayashi et al., 2009). Nonetheless, such planning is seemingly gaining some momentum. Perhaps tellingly it is most commonly undertaken in areas at known high disaster risk; for instance, in Tokyo, Los Angeles and the state of Florida. It is, for example, currently a requirement for coastal communities in Florida but only encouraged in inland communities - presumably attributable to the state's hazard profile (FDCA and FDEM, 2010). In these localities the political will and resources are evidently more forthcoming. It is noteworthy, however, that not all risks are known.

\section{Post-disaster activities}

When a disaster event occurs, response and recovery activities pre-planned or not, are initiated. Response involves immediate actions to save life and property, including search and rescue, sheltering and the re-establishment of access and communications. This eventually transitions into recovery where efforts are geared more directly towards the re-establishment of livelihoods, living conditions and ultimately to the restoration of some sense of normality.

One of the central features of the post-disaster period is the desire to act quickly. This can naturally come into conflict with the need for planning and careful deliberation (Olshansky and Chang, 2009). Haste can be particularly important in the immediate aftermath of disaster events as human life may depend directly on the speed of an intervention. In anticipation of this, provisions often exist so that normal legislative procedures can be circumvented in emergency situations (Le Masurier et al., 2006). However, while this can be advantageous in the short-term, such arrangements can obviously be problematic if alternative procedures are not defined and haste is allowed to completely overshadow contemplation as it can lead to a greater chance of errors occurring, including those that ultimately put a community in further peril (e.g. environmental degradation and the promotion of disaster recurrence). Such provisions less frequently exist for activities in the disaster recovery period (Le Masurier et al., 2006). However, as Le Masurier et al. 
(2006) have noted, this can also be problematic as a need for haste can exist beyond that which can be accommodated by routine procedures. As a result, in the past, special arrangements have been developed reactively in recovery operations, although in circumstances less than optimal. For instance, in Aceh Province and Nias, Indonesia, following a series of tsunamigenic earthquakes in 2004 and 2005, an accelerated EIA procedure was decreed by the Ministry of Environment (Gore and Fischer, 2014).

These circumstances highlight the potential utility of planning in the pre-disaster period. Pre-disaster recovery planning, in particular, has been strongly advocated on the grounds that it could help reconcile the conflict between rapidity and contemplation and facilitate both the hasty implementation of recovery measures and the quality of these actions. The term "quality" here relates to both the general betterment of the overall state of the living environment in the impacted locality, and, in particular, to the reduction of disaster risks (Mileti, 1999). Although governments often note practical challenges, due to the perceived need for urgent action (UNISDR, 2013), the recovery period can offer important opportunities for risk reduction. Olshansky and Chang (2009) have attributed this to a number of factors: firstly, the inflow of finance to the impacted locality which often accompanies such events. This can originate from domestic sources, and, as is particularly the case in developing countries, from the international community. Secondly, the widespread need for new construction. In work by Olshansky et al. (2012) this was related to the idea of "time compression" where the event essentially results in a compression in the normal cycle of infrastructure expiry and replacement. This can create a rare and important opportunity to reshape or relocate a settlement in the interests of reducing risk. Finally, the increased awareness of disaster issues generated by the event can open a window of opportunity to push for risk reduction; a disaster can constitute a "focusing event", which can present a key, yet short-lived, opportunity for policy change (Kingdon, 1995). Through the prior consideration of such measures it is held that the pre-disaster recovery planning process can help better capitalise on these opportunities (Berke and Campanella, 2006). Indeed, a comparative study undertaken by $\mathrm{Wu}$ and Lindell (2004) looking at housing reconstruction, appears to provide support for the claim that pre-disaster recovery planning could both hasten the speed of reconstruction and improve the integration of risk reduction measures into the recovery effort.

\section{Three potential opportunities for integration}

From their review of literatures, Gore and Fischer (2014) identified two points related to the role of EA in a disaster management context. One was that EA could 
be utilised to better mainstream disaster management into development activity by integrating an explicit disaster risk consideration into the EA process, and the other was that EA should be integrated into activities in the aftermath of disaster events to contribute to the prevention of disaster recurrence and the promotion of sustainable development. The first of these reflects broader trends towards expanding the scope of EA to wider sustainability issues, including both social and economic factors, by means of Sustainability Assessment. This means that an assessment of the impact on disaster risk, which is normally undertaken only for actions directly aimed at reducing disaster risks (e.g. structural flood mitigation measures), would be undertaken for every action in an integrated manner with the impact of other components of sustainable development. Developing EA in this manner could not only directly contribute to disaster risk reduction, but could provide a means of raising public awareness of disaster risks and thus contribute to this objective more indirectly. Benson (2007) identified two ways through which EA could be enhanced to this end; firstly arguing that EA should include an explicit consideration of the disaster risk impacts of development activities through their impact on the environment; secondly, advocating the expansion of these tools to promote a consideration of the potential impact of environmental conditions, including hazards, on proposed development activities. Interestingly, data collected concerning the project level of assessment as part of the Hyogo Framework for Action monitoring process for the period 2011-13, indicates that $74 \%$ of states (of 73 reporting $^{2}$ ) perceived that impacts of disaster risk were taken into account in EIA. ${ }^{3}$ However, it is frequently unclear exactly how disaster risks are taken into consideration and there is often an acknowledgement, even by those governments answering positively, that an explicit requirement to consider disaster risk in EIA is absent.

The second point, i.e. the integration of EA into activities in the aftermath of disaster events, reflects the widely acknowledged necessity for disaster risk reduction to be an essential activity in the period following the occurrence of such events. Indeed, the post-disaster period can offer important opportunities for this. However, a central concern with regards to this objective are the contextual complexities associated with the post-disaster period. In response to these, two strategies may be concerned with furthering this ambition (following Gore and Fischer, 2014), which lead us to another two integration opportunities for EA and disaster management. The first is the development of an accelerated form of EA

\footnotetext{
${ }^{2}$ From a review of all final reports posted on www.preventionweb.net as of 11th March 2014.

${ }^{3}$ That is, answering positively to the question: "Impacts of disaster risk taken account in Environment Impact Assessment (EIA)"?
} 
for implementation in post-disaster situations. This could help to ensure that environmental considerations are taken into account to prevent secondary risks emerging, while helping to satisfy the desire for haste in undertaking response and recovery activities after a disaster occurs. Although, depending on the strategy adopted, there is a danger that any procedural acceleration could be detrimental to the quality of the procedure and as a result any such attempts could be criticised for being myopic in circumstances when this is unavoidable (e.g. politically untenable not to do so), acceleration could seemingly have advantages over a complete absence of such an assessment. It could also have potential advantages over accelerated approaches devised reactively in the post-disaster period by allowing for their formulation in the relative calm and stability of the pre-disaster period and their application absent of any design and implementation lag. The second is to draw on the opportunity created by the practice of pre-disaster planning. This could allow for the application of EA outside of the constraints of the post-disaster period with obvious potential benefits for the quality of the procedure. In particular, this could relate to community engagement which, despite its importance, could be particularly difficult following disaster events owing to issues like public preoccupation with personal tragedy and impatience with consultations that can be seen to be delaying much needed physical action (Steinberg, 2007). Indeed, as previously noted, public involvement is already proclaimed as a key principle of pre-disaster recovery planning, something that the EA process could promote; although its ability to do this in practice is not without problems. It could also aid the hasty implementation of post-disaster actions, as they would potentially be less impeded by the necessity to undergo such assessments in the disaster's aftermath.

Accordingly, in line with the above, three areas of potential integration between EA and disaster management are defined in this study: (1) the integration of explicit disaster risk considerations into EA tools, (2) the development of accelerated EA for application in post-disaster situations, and (3) the integration of EA

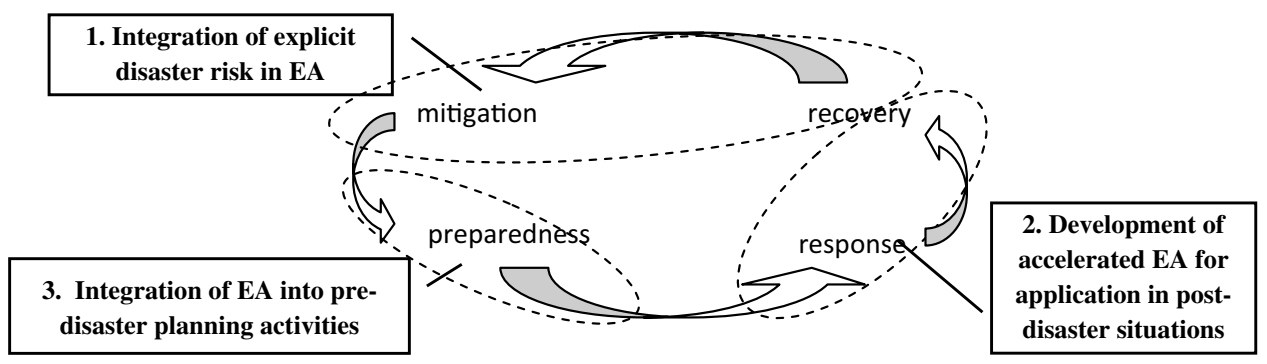

Fig. 2. Potential role of EA mapped onto a typical representation of the Disaster Management Cycle. 
into pre-disaster planning activities. The first type of integration is mainly concerned with the later recovery phase to the mitigation phase within a routine development context. The second type is concerned mainly with the response phase to the early recovery period. The third, finally, is mainly relevant for the preparedness phase, as pre-disaster response and recovery planning is regarded as the main preparedness activities. These are shown in Fig. 2. The following discussions will revolve around these three points.

\section{Current State of Research and Practice}

\section{Identification of existing literatures}

In order to clarify how far the integration of EA and disaster management has been researched to date, and in which areas further effort is needed, existing professional literatures on EA and disaster management were reviewed. The review was undertaken in three steps. Firstly, papers were extracted from two academic literature databases, namely the Web of Science () (Thomson Reuters) and SwetsWise online content (SwetsWise). The web based survey was conducted on 18 December 2013, under the conditions listed in Table 1. Research articles that included any search words related to "environmental assessment" and "disasters" either in its title, abstract, or keywords were identified. All combinations of search words were tested and recorded. After that, simple duplications in search results were excluded (e.g., search results of "environmental assessment" duplicates with search results of "strategic environmental assessment"). Secondly, papers that were not using our definition of EA or disaster management were excluded. This

Table 1. Conditions of the web based survey.

Year of publication

Publication type

Scope of search

Search word 1 (EA related words)

Search word 2 (Disaster related words) ${ }^{\mathrm{a}}$ 1994-present (18. Dec. 2013)

Journal article (conference proceedings, news articles, editorials were excluded)

Title, keywords, abstract

"environmental assessment", "strategic environmental assessment", "environmental impact assessment", "sustainability assessment", "sustainability appraisal"

Disaster, hazard, earthquake, tsunami, flood, landslide, hurricane

\footnotetext{
a"Vulnerability" was considered unnecessary here as it was assumed that whenever this term is used within the context of disaster management, "disaster", "hazard", or other terms that indicate a specific hazard type (i.e. "earthquake", etc.) should be used in combination.
} 
Table 2. Criteria for the screening work.

\begin{tabular}{ll}
\hline Criteria for Environmental Assessment & - Assessment undertaken in an ex-ante manner \\
& - Assessment of a human action (project, plan, policy) \\
& - Is a process, rather than a one-shot simulation \\
& practice/method \\
- & Includes an environmental aspect in its scope of \\
& assessment \\
Criteria for Disaster Management & Concerns natural hazards \\
- & Is related to disaster management action (e.g. papers \\
& discussing projects in floodplains are excluded if \\
& disaster (flood) risks are not discussed) \\
- & Papers that only recommend the use of EA for \\
& disaster management with no detailed discussion are \\
& excluded \\
Other considerations & Papers in English language \\
\hline
\end{tabular}

screening work was done by reviewing the abstracts (and referring to the main text whenever necessary) based on the criteria listed in Table 2, which derives from our understanding of EA and disaster management presented in the previous chapters. In the final step, the main text of the remaining papers were reviewed in detail to clarify how the integration of EA and disaster management was discussed. Papers were excluded at this step if the use of EA for disaster management and their integration were not discussed.

\section{Overall trend}

The review revealed that while 325 papers included both EA related words and disaster related words, only 19 were related to our understanding of EA and disaster management, and 16 of them included integration aspects. From Fig. 3, which shows the origin of the 16 papers, we can see that $37 \%$ come from the EA community and $68 \%$ from the environmental science community. Only $13 \%$ come from the disaster management community. This result suggests that EA has not attracted much attention from the disaster management research community to date as a potential tool for disaster management. In terms of publication year, an increasing trend was observed (Fig. 4). This trend is consistent with the general increase observed in the number of natural hazards occurring worldwide (EM-DAT), and with the increase of attention in the policy arena (e.g. introduction of EU Flood Directive in 2007, explicit reference to EIA in the Hyogo Framework for Action in 2005). In sum, it is suggested that the integration of EA and disaster management has not been researched extensively, but there are signs of growing 


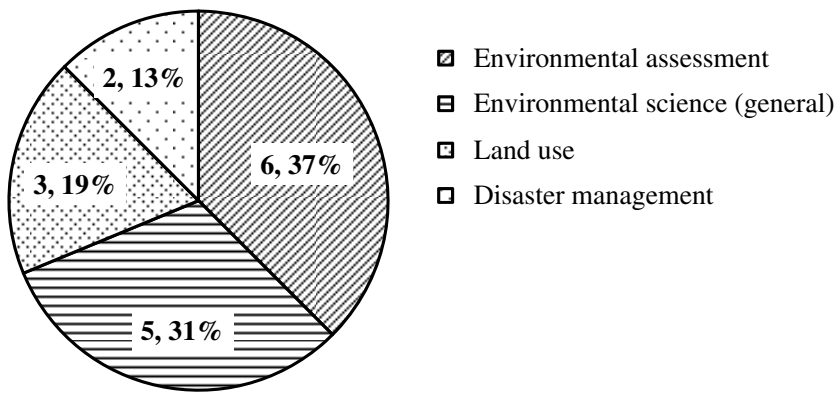

Environmental assessment: Environmental Impact Assessment Review, Impact Assessment and Project Appraisal, Journal of Environmental Assessment Policy and Management; Environmental Science (general): Journal of Environmental Management, PNAS of the USA, Earth-Science reviews, Ecological Indicators, Geomorphology; Land use: disP-the Planning Review, Land Use Policy, Journal of Landscape Architecture; Disaster management: Disaster Advances

Fig. 3. Paper origin.

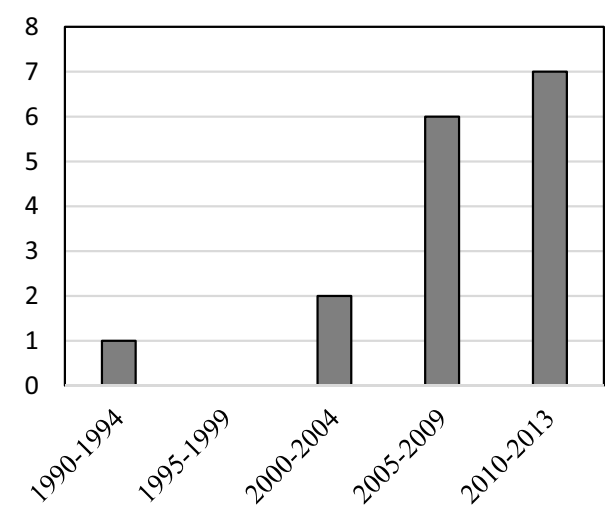

Fig. 4. Year of publication.

interest in integrating environment and disaster considerations. Overall, within the 325 papers, attempts to integrate disaster risk consideration in other environmental management tools (e.g. geo-environmental impact assessment (Huang et al., 2012), ecological risk assessment (Ohlson and Serveiss, 2007)), and attempts to integrate environmental consideration in disaster management tools (Dong et al., 2013) were also evident.

\section{Current state of EA-disaster management integration research}

The review of the 16 papers revealed that the integration of EA and disaster management has been mainly discussed in terms of an explicit disaster risk 
Table 3. Analysis of papers concerned with EA and disaster management integration.

\begin{tabular}{|c|c|c|c|}
\hline & Integration type ${ }^{b}$ & EIA/SEA/SA & Hazard type \\
\hline Cavallin et al. $(1994)^{\mathrm{a}}$ & type 1 & EIA & $\begin{array}{c}\text { geomorphologic hazard } \\
\text { (e.g. landslide) }\end{array}$ \\
\hline Greiving $(2004)^{\mathrm{a}}$ & type 1 & SEA & non-specific \\
\hline Gunther and Winfre (2005) & type 1 & EIA & landslide, flood \\
\hline Kuo and Chiu (2006) & type 1 & SEA & landslide \\
\hline Geneletti (2008) & type 1 & SEA & landslide \\
\hline Bruns et al. (2008) & type 1 & SEA & flood \\
\hline Carter et al. (2009) ${ }^{\mathrm{a}}$ & type 1 & SA/SEA & flood \\
\hline Helborn et al. (2011) & type 1 & SEA & flood \\
\hline Lee (2011) & type 1 & EIA & earthquake \\
\hline Geneletti (2012) & type 1 & SEA & flood \\
\hline Sidle et al. (2013) $)^{\mathrm{a}}$ & type 1 & $\mathrm{SA}$ & non-specific \\
\hline Xu et al. (2013) & type 1 & EIA & earthquake, landslide \\
\hline Douven and Buurman (2013) ${ }^{\mathrm{a}}$ & type 1 & EIA & flood \\
\hline Kelly $(2002)^{\mathrm{a}}$ & type 2 & not specified & non-specific \\
\hline Spaling and Vroom (2007) ${ }^{\mathrm{a}}$ & type 2 & EIA & non-specific \\
\hline Liu and Duan (2010) ${ }^{\mathrm{a}}$ & type 2 & EIA & earthquake \\
\hline
\end{tabular}

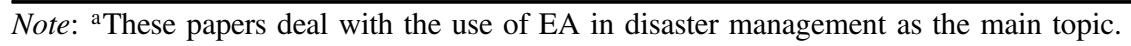

bType 1 refers to "Integration of explicit disaster risk in EA", and type 2 refers to "Development of accelerated EA for application in post-disaster situations".

consideration in EA, which is followed by efforts related to accelerated EA for post-disaster situations (Table 3). However, no study to date has addressed the issue of integrating EA into pre-disaster planning activities. No other form of EAdisaster management integration was found. These findings are consistent with the integration efforts made by international development organizations in their EA guidelines (Benson, 2007). Among the 16 papers, 8 discussed the integration of EA and disaster management as the main topic, whereas the rest partially mentioned or reported on the topic.

With regards to considering the integration of an explicit disaster risk concern in EA (type 1 in Table 3), two trends were observed. Firstly, disaster risks are addressed in EA from two perspectives, i.e. impact of disaster risks on human development actions and vice versa. It is notable that the earliest contribution, which was published nearly 20 years ago, already articulated the necessity to examine (geomorphologic) hazards in EIA from these two perspectives. The case studies that discuss the impact of human development actions on disaster risks (i.e. Xu et al., 2013; Kuo and Chiu, 2006; Bruns et al., 2008; Gunther and Winfrey, 
2005) mention the risk of human development action induced hazards. On the contrary, none specifically paid attention to the vulnerability dimension (e.g. social aspects) in disaster causation, in spite of their suggested significance (e.g. Viljoen et al., 2001; Mahmoudi et al., 2013); for instance, a development action that has a detrimental impact on the livelihood or food security of a community could also increase the risk of disaster regardless of its impact on a particular hazard. Secondly, there are more studies on integrating disaster management with SEA than EIA. For example, Carter et al. (2009) demonstrated the potential of SEA in reducing the risk of flooding from case studies in England, attempted by translating flood risk management policy into spatial planning through SEA inclusive sustainability appraisal (SA). This reflects the notion that disaster management should adopt a multi-hazard approach (Quarantelli, 1997; Perry and Lindell, 2003), as it could only be addressed at the strategic level of decision making.

Three publications specifically focused on the post-disaster use of EA (type 2 in Table 3), each dealing with slightly different disaster management phases. Kelly (2002) introduced a guideline (updated by Kelly, 2005) for rapid environmental assessment (REA) which is applied post-disaster as part of the disaster response effort. REA is generally broader in scope than traditional statutory EA and identifies and prioritizes relief activities by identifying environmental threats associated with the disaster, the unmet basic needs that could potentially lead to adverse environmental impacts, negative environmental consequences of relief options, and the gap between the cognition of relief agencies and the stricken community. It has been developed for use primarily in developing countries and to not necessitate input from environmental specialists. It uses a simple qualitative methodology built around checklists and rating tables. While the focus of REA is on disaster response, (normally within 120 days after disaster occurrence), Spaling and Vroom (2007) discussed the role and utility of EA in the design and implementation of proposed rehabilitation and reconstruction projects at the community level (e.g. constructing family houses, drilling wells, repairing schools, etc.) that are part of the recovery activities from a tsunami related disaster (focusing on the Sumatra-Andaman earthquake). This EA, called community EA, was applied to small scale projects with less detailed information for the rapid identification of potential impacts. Equitable participation of beneficiaries and the use of documented information, observation and professional opinion rather than extensive scientific studies are key characteristics. Research activity around this type of integration is still scarce, especially regarding academic case studies on actual implementation. 


\section{Potential Means of Integrating Disaster Management and EA: A Discussion}

In this section the three forms of integration are discussed further, in terms of merits/problems of the idea and relevant techniques, drawing particularly on the outputs of our literature survey and the Tokyo workshop (see Gore et al., 2012). ${ }^{4}$ The content of the Tokyo workshop was structured around the consideration of the three areas of potential integration and engaged a total of 20 individuals from the environmental management and disaster management communities in the UK and Japan (practitioners, academics and students). Sub-groups discussed issues using a SWOC (strengths, weaknesses, opportunities and challenges) analysis framework. In line with this framework, for each area of potential integration, participants were asked to contemplate the strengths and weaknesses of the idea and the opportunities and challenges for progressing it.

\section{Integrating explicit disaster risk considerations into current EA tools}

To a large extent the attractiveness of this proposition rests on the fact that EA is an already widely established tool (Greiving, 2004; Gore et al., 2012). EIA has been practiced for several decades in now over 200 countries worldwide, SEA is also increasingly being adopted and the associated body of literature is growing quickly (Fischer and Onyango, 2012). Expanding EA to incorporate explicit disaster risk considerations could be a cost-efficient way of promoting disaster risk reduction. Indeed, there has recently been evident movement in some parts of the world towards this. In the EU, for instance, a recent proposal from the European Commission to amend the EIA directive (2011/92/EU) includes the issue of disaster risk as an explicit concern though its inclusion as an environmental component (EC, 2012).

However, a number of associated issues were discussed in the Tokyo workshop. Firstly, in many countries other tools and mechanisms for addressing disaster risk are already firmly established (e.g. Flood Risk Assessment in the UK; see Hayes, 2012). Thus the usefulness of integration will vary. Our literature survey also found new approaches discussed in academia, such as geo-environmental impact assessment (as mentioned earlier). There is obviously a need to avoid overlap with existing mechanisms and inefficiencies through duplication. At the same time, the risk of losing the strong disaster risk management element by fully integrating these existing tools with EA should also be noted (see e.g. Therivel and Fischer, 2012; Tajima and Fischer, 2013). Secondly, despite the

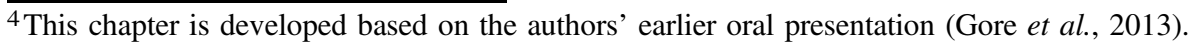


propagation of EA systems around the world, experiences have not been uniform and always completely successful. In developing countries, in particular, weaknesses in EA practice have often been reported (e.g. Douven and Buurman, 2013). These pertain to issues like insufficient access to human resources, lack of enforcement and the low status of the relevant ministry or responsible agency (Glasson et al., 1999; Boyle, 1998; Lohani et al., 1997). Subsuming disaster risk considerations within EA could mean that efforts to reduce disaster risk are also constrained by the factors that constrain EA in some contexts (see e.g. Arts et al., 2012). For example, in Japan, assessment outcomes have had a limited impact on decision making due to sectionalism resulting in minor changes to proposals only, and the "no action" alternative is not considered which could limit the extent to which risk avoidance becomes a viable option (Harashina, 1998, 2001). The expansion of EA in this manner could even be detrimental to existing practice where resources are scarce. Such arrangements could, for instance, foreseeably have financial implications for administrative agencies and an expansion of requirements without additional budgetary and resourcing support could have broader implications for EA practice in some localities.

From a practical standpoint, the expansion of EA in this manner would inevitably lead to new demands on expertise. In this context, it would be important to link EA with, and utilise, the existing disaster management infrastructure. For instance, area specific risk assessments that are conducted and maintained in many countries to determine area specific risk profiles (e.g. as is a requirement in the UK under the Civil Contingencies Act, 2004) could be an important screening and scoping input. In fact, the literature review showed that the current practice of incorporating disaster risk considerations in EA often relies on other information sources, such as hazard maps or hydraulic studies (Geneletti, 2012, 2008; Gunther and Winfre, 2005). Methods developed for disaster risk assessment in the disaster management research community could be also utilized (e.g. Disaster Risk Index (Peduzzi et al., 2009); and Vulnerability Analysis (Wei et al., 2004)). Regarding the analysis of cumulative impact of human actions on disaster risks, integration of SEA or cumulative EA with Disaster Incubation Analysis (DIA) could be an option (Mulvihill and Ali, 2007). These tools could, to some extent, help in dealing with the uncertainty problem, i.e. the difficulty of accurately predicting future disaster risks and their impacts, pointed out in the workshop (Gore et al., 2012); although, it is impossible to fully eliminate uncertainty in predicting disaster risks. In this sense, it would also be essential from both an efficiency perspective and a risk management perspective to fully engage stakeholders. In particular, existing disaster management/emergency planning agencies could, for instance, act as consultees at various stages of the EA process. In fact, enhanced stakeholder involvement has 
been pointed out by scholars as a major benefit of integrating disaster risk consideration in EA (Carter et al., 2009; Bruns et al., 2008; Douven and Buurman, 2013), as disaster management becomes inevitably more interdisciplinary, and one of the major contributions of EA to date has been the enhancement of communication (Fischer et al., 2009). Accordingly, how to present the disaster risks integrated with other environmental concerns, and how stakeholders perceive those outputs, would become of major concern for future studies.

In terms of practice, data collected as part of the Hyogo Framework for Action monitoring process suggests that the consideration of disaster risks in EA is currently somewhat existent, even if only in a limited ad hoc manner. Unfortunately, there exists only very limited information regarding how this is done, to what degree it is done, and how successful it is. As for existing guidelines, CDB and CARICOM (2004) provided guidance on Natural Hazard Impact Assessment Environmental Impact Assessment (NHIA-EIA). This suggests opportunities for further empirical study, for instance, effectiveness studies on institutional learning and awareness raising of disaster risks (see Jha-Thakur et al., 2009).

\section{Developing accelerated EA procedures for application in post-disaster situations}

The application of accelerated EA procedures in post-disaster activity was believed to have the potential to enhance transparency, information collection, sustainability, and speed of decision making (Gore et al., 2012). The acceleration of EA could take a variety of forms and the way that these would play out depends on the nature of EA in a locality. At a fundamental level this could be achieved by refining the extent of the assessment to take account of the urgency required. Some approaches suggested in the Tokyo workshop included, for instance, only focusing the assessment on the environmental issues perceived to be most critical; reducing the extent of the environmental survey period; orientating the assessment more heavily towards expert judgement as, for example, seen in JICA's environmental and social consideration system (Gore et al., 2012). In the context of EIA under the European EIA directive, a "part-stage" assessment where EIA only covers some stages of a multiple stage project has also been mentioned (EC, 2006). Approaches like REA and community EA both make use of such approaches to promote rapidity; with an REA capable of be completion in as little as a few hours (Kelly, 2005). Other arrangements could include adapting or streamlining the administrative process through supplementary resourcing, e.g. to reduce review periods. This was done in some parts of Indonesia following the 2004/2005 earthquakes to hasten the scoping process (Gore and Fischer, 2014). Other means 
to accelerate the EA process could involve undertaking ex-post EAs after activities have been initiated (EC, 2006).

The obvious issue associated with acceleration is that of procedural quality loss. This could increase the risk of missing significant impacts that would have been identified under normal procedural requirements. Furthermore, it could also be detrimental to community engagement and consensus building, which have been found to be of fundamental importance for the mental health and healing of affected communities (Kamani-Fard et al., 2013); although, as was noted previously, this can be particularly challenging in post-disaster contexts. Each of the above examples would, however, entail different speed/quality trade-offs, the exact nature of which would depend to differing degrees on the national or regional contexts. The level of tolerable quality loss might also deviate from the norm, depending on the severity of the damage.

For approaches that could foreseeably entail some quality loss, important considerations when contemplating their application would be the nature of the proposed development action and the importance of urgency attached to the action. With regard to the first point, quality loss associated with acceleration may be considered less acceptable in some cases than others, depending on issues like the nature of the potential impacts associated with the proposed activity (e.g. the associated certainty/uncertainty, longevity, etc.) and the degree of community engagement and consensus building believed necessary. Accordingly, while quality loss may be deemed acceptable for some actions in certain situations, some activities may be judged unsuitable to undergo any form of accelerated procedure that could compromise its quality. For example, accelerated EA might be considered appropriate for immediate temporary housing but not for long-term housing solutions, as community engagement becomes essential in the latter case (Gore et al., 2012). In reference to the second point, the circumstances surrounding the proposal would also be a central consideration. For instance, in a situation where human life is in immediate danger (mainly in the initial response phase) there will generally be greater justification for procedural quality loss for the sake of accelerating an action than in a recovery situation where this is not the case even though there is a desire for haste at a level above that of a normal situation. In cases like the latter, approaches to acceleration that entail a loss of quality might not be justifiable.

Where quality loss could be associated with the approach, the above points should accordingly be considered in the pre-disaster design process (including the "trigger") of any accelerated EA approach in order to help reduce the risks associated with accelerating response and recovery actions. Accordingly, the role of screening could be particularly important upon implementation. Screening would be an essential stage where a decision to apply a pre-defined special EA 
arrangement, such as an accelerated EA process omitting a procedural stage, is made. This could be aided, for example, by the pre-disaster development of a screening list where levels of EA for each development type in a post-disaster context are prescribed (Gore et al., 2012). Scoping could also be an important stage in assuring procedural quality under acceleration, depending on the approach adopted. As Glasson et al. (1999: 91) have noted, scoping allows limited resources, in this case time, to be "allocated to best effect". It also contributes "to the production of a concise and focused environmental report" (Fischer and Phylip-Jones, 2008: 142). The importance of scoping has also been highlighted by e.g. Spaling and Vroom (2007) and by Tokyo workshop participants. It would allow case-by-case consideration of the form and extent of acceleration, and could have positive effect on consensus building (Gore et al., 2012). However, the effectiveness of scoping in post-disaster EA will depend on the characteristics of the particular EA system. For instance in Japan, the EIA scoping stage has actually been criticised by some as a mere formality in the normal development context (Hayashi, 2008) and following the 2011 Tōhoku Earthquake a special EIA process for certain recovery projects was formally introduced which omitted the scoping stage $^{5}$ (Shibata, 2012). Empirical studies regarding accelerated EA approaches, including the Japanese case, would be beneficial in further developing these ideas by systematically establishing the relationship between benefit (e.g. the extent of acceleration) and cost (e.g. enhanced environmental risk and detrimental social impact) of a proposed acceleration approach, within its implementation context (e.g. disaster characteristics, local setting, characteristics of the EIA system applied in normal situation).

The idea of tiering between post-disaster EAs at different levels highlighted by Spaling and Vroom (2007) also warrants attention in the context of acceleration. Here, different types of EA are used with regard to their strength and conditions and are integrated to inform each other. A well tiered approach could thus perhaps have efficiency benefits and generate time savings. Indeed, the reduction in time and costs required for project level EIA has long been spouted as a potential benefit of SEA in a tiered system (Fischer, 1999; Abaza et al., 2004); although evidence of this is still limited (Therivel and Morris, 2009). The development of simple assessment techniques that support transparent and rational assessment is another factor. For example, the rapid impact assessment matrix (RIAM) is a matrix based technique to improve impartiality of subjective (experience and intuition based) judgement in EA (Gilbuena et al., 2013), which could potentially be used under difficult post disaster circumstances (e.g. lack of information, time

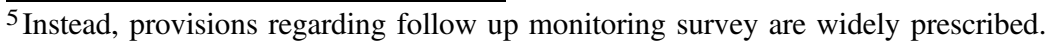


pressure). Tools such as Environmental Needs Assessment (ENA) (UNEP, 2008), in which the environmental setting of post-disaster situation is analysed in a timely and efficient manner, could help such post-disaster screening and scoping practice.

Irrespective of the procedural approach, the conditions in the post-disaster period could be a significant constraint to post-disaster EA. For example, there may be staff losses at key agencies, damaged facilities and equipment, and abnormal levels of demand above that which the normal implementing infrastructure was designed to accommodate (Gore and Fischer, 2014). Supplementary measures to ensure sufficient implementation capacity would accordingly also be an important consideration alongside the development of any accelerated EA arrangements. This could, for instance, include establishing mutual assistance agreements between national counterpart agencies separated geographically and establishing broader business continuity management arrangements in key organisations (Gore and Fischer, 2014).

\section{Integrating EA methods into pre-disaster response and recovery planning activities}

The integration of EA within pre-disaster planning activities and the application of EA in the pre-disaster period offers potential advantages for the quality of the procedure when considering some of the contextual constraints identified above associated with the post-disaster period. It also offers potential benefits in terms of the enhancement of inter-sectoral coordination in the pre-disaster planning process. As Douven and Buurman (2013) note, different sectors have different perspectives on disasters and how to deal with them. In addition, the learning function of EA (see e.g. Jha-Thakur et al., 2009) could help develop institutional capacity regarding disaster respons. While these views were supported by the Tokyo workshop participants and by some other authors (e.g. Srinivas and Nakagawa, 2008), this does raise other challenges.

Notably, "uncertainty" was emphasized by the Tokyo workshop participants as the major challenge. The post-disaster environment may differ considerably to that at the time of planning the response and recovery interventions which could inject additional uncertainty into the impact assessment process. Such changes could be attributable to the disaster agent itself, e.g. a tropical cyclone or tsunami could lead to the loss of a large area of wetland habitat. They could also change simply through the time that elapses between planning the action and its implementation as this period could be extensive and uncertain; under many legislative regimes authorisations based on EAs can in fact become invalid after a set period of inaction for this reason (examples include e.g. Canada and the US). This could 
have implications not only for impact prediction, but also for evaluation due to contextual changes leading up to and following the event (e.g. changing public opinion or environmental standards used in the evaluation process). This would have repercussions for the form of any assessment conducted in this manner. It is unlikely, for instance, that a comprehensive assessment could be a static, "one-off", process. Currently advocated pre-disaster planning practices already include, for instance, regular reviews, periodic updates (e.g. every 3-5 years), and post-event reviews and refinements as part of the procedure (e.g. IRP, 2012). Thus, it may still be necessary to conduct some assessment work inside the postdisaster period. In light of this, approaches like generic EA may offer some potential (Gore et al., 2012). This is an approach that has been employed in absence of site specific information and could provide a basis for more thorough EA in the post-disaster period. ${ }^{6}$ In conducting such an assessment, studies that establish the environmental, social, and economic impacts of disaster agents would help understand the post-disaster conditions where response action takes place (e.g. Srinivas and Nakagawa, 2008; Du et al., 2012).

The potential associated with this approach is also obviously limited by the extent of pre-disaster planning undertaken. Currently, such planning is not practiced comprehensively or universally. As noted earlier, there is generally a greater emphasis on planning for response than recovery, and the situation differs between and even within countries (see, for example, the case of Florida mentioned previously). In many countries such planning is constrained by insufficient resourcing (UNISDR, 2013). It is perhaps notable, however, that global efforts under Priority 5 of the Hyogo Framework for Action ("strengthen disaster preparedness at all levels"), which incorporates pre-disaster planning, is an area showing on-going advancement (UNISDR, 2013). In addition to the extent of pre-disaster planning carried out, the opportunity available to assess actions in advance will also be

\footnotetext{
${ }^{6}$ There is currently no commonly agreed upon definition of generic EA. However, there are examples, such as one in the State Environmental Quality Review of the state of New York. These define generic EA as follows: "Generic EISs may be broader, and more general than site or project specific EISs and should discuss the logic and rationale for the choices advanced. They may also include an assessment of specific impacts if such details are available. They may be based on conceptual information in some cases. They may identify the important elements of the natural resource base as well as the existing and projected cultural features, patterns and character. They may discuss in general terms the constraints and consequences of any narrowing of future options. They may present and analyse in general terms a few hypothetical scenarios that could and are likely to occur." (6 NYCRR Part 617.10; Department of Environmental Conservation, 1995). A generic SEA has, for example, been undertaken in the UK as part of the process of developing a geological disposal facility for radioactive waste (Entec, 2010).
} 
conditioned by the nature of this planning, particularly in terms of its content and level of detail. Anticipating hazards and disasters is associated with much uncertainty which can make determining detailed response and recovery actions in advance difficult. We have already noted the difficulties associated with the uncertainties regarding the nature of the receiving environment after disaster, but the precise details of the response and recovery actions that will be needed are also difficult to determine accurately in advance. Indeed, in many instances, despite the existence of a well thought out pre-disaster plan, it will be necessary to plan some actions post-event after the necessity becomes apparent. Thus the potential to integrate environmental considerations into post-disaster actions through integrating EA into pre-disaster planning only goes so far.

Finally, it is also noteworthy that EA legislation, as it stands, may not be supportive to such an undertaking (Swain and Therivel, 2012). In the EU, for instance, the SEA Directive exempts plans and programmes the sole purpose of which is to serve civil emergency from SEA. In accordance with this, guidance prepared by the European Commission reports that "a plan setting out what action should be taken if an avalanche were to occur would be exempt from the Directive" (EC, 2003). As both practice and research towards integration of EA methods into pre-disaster planning seems to be absent, it is still necessary to conceptually develop its specific form, including the framework for revising EA post-disaster, and make suggestions for trial practice.

\section{Conclusion and Recommendations}

Drawing on existing EA and disaster management research, three potential approaches for integration were discussed in this paper. There was found to be some merit in each of the areas. Integrating explicit disaster risk considerations into EA tools could further promote a consideration of disaster risk in the development process, and developing accelerated EA procedures and integrating EA techniques into the pre-disaster planning of post-disaster actions could both help further assimilate EA into post-disaster decision making. In terms of the research effort to date, while the results of our literature survey suggest growing interest of integrating environmental and disaster risk considerations, among those who currently lead the discussion in academia, none focus on the use of EA for predisaster planning for post-disaster activities. A number of issues were also identified that could condition the success and the desirability of each of the concepts. Some of these issues are fundamental to the particular approach (e.g. dealing with high levels of uncertainty), and some relate to the context in which they would be applied (e.g. the nature of existing practices in a particular country or region). 
In order to overcome these issues and further develop this area, some recommendations for future work are provided as follows. Regarding the integration of explicit disaster risk considerations into current EA tools, the development of a methodology to effectively consider the cumulative effects of human action induced environmental degradation on future disaster risks, perhaps in SEA, is an important issue. The effective utilization/integration of existing disaster management tools to consider the impact of disaster risks on human development action in EA is another. Indeed, data collected in the Hyogo Framework monitoring process suggests that the consideration of disaster risks in EA is occurring in some countries, but detailed information is still scarce. Comparative studies looking at this could be beneficial in developing this area further, in particular, those looking at how disaster risks are considered (e.g. impact of development actions on disaster risk, risks to the development actions themselves, and whether hazard and vulnerability dimensions are both considered). For the development of accelerated EA procedures for application in post-disaster situations, further discussion on screening and scoping techniques, with regard to the characteristics of different disaster response/recovery phases, should evolve. A potential challenge here could be the lack of actual application of such EAs in the real world. Studies of concise forms of EA, e.g. the Environmental Assessment under NEPA, could be an alternative platform to empirically discuss the concrete trade-offs between quality and acceleration of EA in general. In terms of integrating EA methods into predisaster response and recovery planning, the development of a methodology of EA to aid the revision and updating of such plans should be considered, particularly post-disaster in the light of the difficulty of addressing uncertainty in predicting post-disaster circumstances. Indeed, while this paper considered these last two areas individually, it appears that a composite approach may be preferable where possible. Here the quality issues that could be associated with an accelerated approach could perhaps be to a degree overcome by being pro-active pre-disaster (e.g. in terms of public involvement) and similarly, the issues with uncertainty in pre-disaster approaches could be addressed by action post-disaster. Future studies should not be limited to this list, but these are issues worth paying attention to for a sustainable and disaster resilient society.

\section{References}

Abaza, H, R Bisset and B Sadler (eds.) (2004). Environmental Impact Assessment and Strategic Environmental Assessment: Towards an Integrated Approach. Geneva: UNEP. 
Alexander, D (2002). Principles of Emergency Planning and Management. Oxford: Oxford University Press.

Arts, J, H Runhaar, TB Fischer, U Jha-Thakur, F van Laerhoven, P Driessen and V Onyango (2012). The effectiveness of EIA as an instrument for environmental governance - A comparison of the Netherlands and the UK. Journal of Environmental Assessment Policy and Management, 14(4), 1250025-1-40.

Benson, C (2007). Environmental assessment. In Tools for Mainstreaming Disaster Risk Reduction, C Benson and J Twigg (ed.), pp. 79-89. http://www.preventionweb.net/ files/1066_toolsformainstreamingDRR.pdf.

Berke, PR and TJ Campanella (2006). Planning for postdisaster resiliency. American Academy of Political and Social Science, 604, 192-207.

Boyle, J (1998). Cultural influences on implementing environmental impact assessment: Insights from Thailand, Indonesia and Malaysia. Environmental Impact Assessment Review, 18(2), 95-116.

Bruns, D, N Haustein and J Willecke (2008). Landscape planning for flood risk management planning with SEA. Journal of Landscape Architecture, 3(1), 24-35.

Caribbean Development Bank (CDB) and Caribbean Community (CARICOM) (2004). Sourcebook on the Integration of Natural Hazards into the Environmental Impact Assessment (EIA) Process. Barbados: Caribbean Development Bank.

Carter, JG, I White and J Richards (2009). Sustainability appraisal and flood risk management. Environmental Impact Assessment Review, 29(1), 7-14.

Cavallin A, M Marchetti, M Panizza and M Soldati (1994). The role of geomorphology in environmental impact assessment. Geomorphology, 9(2), 143-153.

Collins, AE (2009). Disaster and Development. London: Routledge.

Department of Environmental Conservation (1995). 617: State environmental quality review, New York State. http://www.dec.ny.gov/regs/4490.html.

Dong Y, DM Frangopol and D Saydam (2013). Time-variant sustainability assessment of seismically vulnerable bridges subjected to multiple hazards. Earthquake Engineering \& Structural Dynamics, 42(10), 1451-1467.

Douven W and Buurman J (2013). Planning practice in support of economically and environmentally sustainable roads in floodplains: The case of the Mekong delta floodplains. Journal of Environmental Management, 128, 161-168.

Du P, J Chen, C Chen, Y Liu, J Liu, H Wang and X Zhang (2012). Environmental risk evaluation to minimize impacts within the area affected by the Wenchuan earthquake. Science of the Total Environment, 419, 16-24.

EM-DAT: The OFDA/CRED International Disaster Database - www.emdat.be, Université Catholique de Louvain, Brussels (Belgium).

Entec (2010). Geological disposal: Generic environmental and sustainability report for a geological disposal facility. Assessment Report. http://www.nda.gov.uk/documents/ upload/Geological-Disposal-Generic-Environmental-and-Sustainability-Report-for-aGeological-Disposal-Facility-Assessment-Report-October-2010.pdf. 
European Commission (EC) (2003). Implementation of Directive 2001/42 on the assessment of the effects of certain plans and programmes on the environment. http://ec. europa.eu/environment/eia/pdf/030923_sea_guidance.pdf.

European Commission (EC) (2006). Directive 85/337/EEC on the assessment of the effects of certain public and private projects on the environment (EIA Directive), as amended. Clarification of the application of Article 2(3) of the EIA Directive. Luxembourg: European Communities.

European Commission (EC) (2012). Proposal for a directive of the European Parliament and of the council amending Directive 2011/92/EU on the assessment of the effects of certain public and private projects on the environment. http://ec.europa.eu/environment/ eia/pdf/COM-2012-628.pdf.

Fischer, TB (1999). Benefits from SEA application - a comparative review of North West England, Noord-Holland and EVR Brandenburg-Berlin. Environmental Impact Assessment Review, 19(2), 143-173.

Fischer, TB and V Onyango (2012). SEA related research projects and journal articles: An overview of the past 20 years. Impact Assessment and Project Appraisal, 30(4), 253-263.

Fischer, TB and J Phylip-Jones (2008). Scoping in environmental assessment. In Environmental Assessment Lecturers' Handbook, TB Fischer, P Gazzola, U Jha-Thakur, I Belcakova and R Aschemann (eds.). ROAD Bratislava, http://www.twoeam-eu.net, pp. 136-142.

Fischer, TB, P Gazzola, U Jha-Thakur, S Kidd and D Peel (2009). Learning through EC directive based SEA in spatial planning? Evidence from the brunswick region in Germany. Environmental Impact Assessment Review, 29(6), 421-428.

Fischer, TB, P Gazzola, U Jha-Thakur, I Belcakova and R Aschemann (eds.) 2008. Environmental Assessment Lecturers' Handbook. ROAD Bratislava, http:www. twoeam-eu.org.

Florida Department of Community Affairs (FDCA) and Florida Division of Emergency Management (FDEM) (2010). Post-disaster redevelopment planning: A guide for Florida communities. http://www.floridadisaster.org/recovery/documents/Post\%20Disaster\%20Redevelopment\%20Planning\%20Guidebook\%20Lo.pdf.

Geneletti, D (2008). Impact assessment of proposed ski areas: A GIS approach integrating biological, physical and landscape indicators. Environmental Impact Assessment Review, 28(2), 116-130.

Geneletti, D (2012). Environmental assessment of spatial plan policies through land use scenarios - A study in a fast-developing town in rural Mozambique. Environmental Impact Assessment Review, 32(1), 1-10.

Gilbuena, R Jr, A Kawamura, R Medina, H Amaguchi, N Nakagawa and DD Bui (2013). Environmental impact assessment of structural flood mitigation measures by a rapid impact assessment matrix (RIAM) technique: A case study in Metro Manila, Philippines. Science of the Total Environment, 456-457, 137-147. 
Glasson, J, R Therivel and A Chadwick (1999). Introduction to Environmental Impact Assessment, 2nd ed. London: Spon Press.

Gore, T, R Tajima, TB Fischer and S Harashina (2012). Summary of the workshop "The potential role of EA in disaster management”. In Japan-UK Joint Seminar on Policy Integration Between Environmental Assessment and Disaster Management — Proceedings. http://www.nishikiz.depe.titech.ac.jp/JPUK2012/Proceedings_of_the_JP-UK_joint_WS.pdf.

Gore, T, TB Fischer, R Tajima and S Harashina (2013). Policy integration between EA and disaster management. In Proc. 33rd Annual Meeting of the International Association for Impact Assessment. Calgary: Canada. http://www.iaia.org/conferences/iaia13/ proceedings/Final\%20papers $\% 20$ review $\% 20$ process $\% 2013 /$ Policy $\% 20$ Integration $\%$ 20between\%20EA\%20and\%20Disaster\%20Management\%20.pdf.

Gore, T and TB Fischer (2014). Uncovering the factors that can support and impede postdisaster EIA practice in developing countries: The case of Aceh Province, Indonesia. Environmental Impact Assessment Review, 44, 67-75.

Greiving, S (2004). Risk assessment and management as an important tool for the EU strategic environmental assessment. disP - The Planning Review, 40(157), 11-17.

Gunther, P and J Winfre (2005). Biodiversity issues for road reconstruction adjacent to a river with a federally listed threatened fish species. Impact Assessment and Project Appraisal, 23(1), 17-27.

Harashina, S (1998). EIA in Japan: Creating a more transparent society? Environmental Impact Assessment Review, 18(4), 309-311.

Harashina, S (2001). A new stage of EIA in Japan: Towards strategic environmental assessment. Built Environment, 27(1), 8-15.

Hayashi, K (2008). How to improve Japanese EIA legislation by utilizing international experience. In Proc. 28th Annual Meeting of the International Association for Impact Assessment, Perth, Australia. http://www.iaia.org/iaia08perth/pdfs/concurrentsessions/ CS2-1_regional_Hayashi.pdf.

Hayes, S (2012). Consideration of flood risk in UK SEA and SA practice, environmental assessment and disaster events. In Japan-UK Joint Seminar on Policy Integration Between Environmental Assessment and Disaster Management-Proceedings. http://www. nishikiz.depe.titech.ac.jp/JPUK2012/Proceedings_of_the_JP-UK_joint_WS.pdf.

Heide, EA (2005). Importance of evidence-based disaster planning. Ann Emerg Med, 47(19), 34-49.

Helborn, H, M Schmidt, J Glasson and N Downes (2011). Indicators for strategic environmental assessment in regional land use planning to assess conflicts with adaptation to global climate change. Ecological Indicators, 11(1), 90-95.

Huang, S, X Li, Y Wang (2012). A new model of geo-environmental impact assessment of mining: A multiple-criteria assessment method integrating fuzzy-AHP with fuzzy synthetic ranking. Environ Earth Sci, 66(1), 275-284.

International Recovery Platform (IRP) (2012). Guidance note on recovery. Pre-disaster recovery planning. http://www.unisdr.org/files/31963_predisasterrecoveryweb.pdf. 
Jha-Thakur, U, P Gazzola, D Peel, TB Fischer and S Kidd (2009). Effectiveness of strategic environmental assessment - The significance of learning. Impact Assessment and Project Appraisal, 27(2), 133-144.

Kamani-Fard, A, AM Hamdan and OD Remaz (2013). Sense of home place in participatory post-disaster reconstruction. Journal of Environmental Assessment Policy and Management, 15(1), 1350005-1-21.

Kelly, C (2002). Assessing environmental impacts during natural disaster: The development of a rapid environmental assessment methodology. Journal of Environmental Assessment Policy and Management, 4(4), 475-492.

Kelly, C (2005). Guidelines for rapid environmental impact assessment in disasters, version 4.4. Cooperative for Assistance and Relief Everywhere, Inc. (CARE).

Kingdon, JW (1995). Agenda, Alternatives and Public Policy. New York: Harper Collins.

Kuo, N and Y Chiu (2006). The assessment of agritourism policy based on SEA combination with HIA. Land Use Policy, 23(4), 560-570.

Le Masurier, J, JOB Rotimi and S Wilkinson (2006). A comparison between routine construction and post-disaster reconstruction with case studies from New Zealand. In Procs 22nd Annual ARCOM Conference. Birmingham, UK.

Lee, HC (2011). Integrated assessment method for the flood management project in Taiwan. Disaster Advances, 4(4), 45-52.

Liu, Y and X Duan (2010). Environmental impact assessment of post earthquake restoration and reconstruction. Disaster Advances, 3(4), 105-109.

Lohani, BN, JW Evans, RR Everitt, H Ludwig, RA Carpenter and S-L Tu (1997). Environmental Impact Assessment for Developing Countries in Asia. Volume 1 - Overview. Manila: Asian Development Bank.

Mahmoudi, H, O Renn, F Vanclay, V Hoffmann and E Karami (2013). A framework for combining social impact assessment and risk assessment. Environmental Impact Assessment Review, 43, 1-8.

Mileti, DS (1999). Disasters by Design: A Reassessment of Natural Hazards in the United States. Washington DC: Joseph Henry Press.

Ministry of the Environment, Japan (2012). The Fourth Basic Environment Plan-Cabinet Decision on April 27, 2012. http://www.env.go.jp/policy/kihon_keikaku/plan/plan_4. html.

Mulvihill, PR and SH Ali (2007). Disaster incubation, cumulative impacts and the urban/ex-urban/rural dynamic. Environmental Impact Assessment Review, 27(4), 343-358.

Nakabayashi, I, S Aiba and T Ichiko (2009). Pre-disaster restoration measure of preparedness for post-disaster restoration of Tokyo. Journal of Disaster Research, 3(6), 407-421.

Ohlson, DW and VB Serveiss (2007). The integration of ecological risk assessment and structured decision making into watershed management. Integr Environ Assess Manag, 3(1), 118-128. 
Olshansky, RB, LD Hopkins and LA Johnson (2012). Disaster and recovery: Processes compressed in time. Natural Hazards Review, 13(3), 173-178.

Olshansky, R and S Chang (2009). Planning for disaster recovery: Emerging research needs and challenges. Progress in Planning, 72, 200-209.

Peduzzi, P, H Dao, C Herold and F Mouton (2009). Assessing global exposure and vulnerability towards natural hazards: The disaster risk index. Natural Hazards and Earth System Sciences, 9, 1149-1159.

Perry, RW and MK Lindell (2003). Preparedness for emergency response: Guidelines for the emergency planning process. Disasters, 27(4), 339-350.

Quarantelli, EL (1997). Ten criteria for evaluating the management of community disasters. Disasters, 21(1), 39-56.

Randall, J and E Jowett (2010). Green recovery and reconstruction toolkit-Environmental impact assessment tools and techniques. San Francisco: World Wildlife Fund. http:// green-recovery.org/wordpress/wp-content/uploads/2010/11/Module-3-Content-Paper. pdf.

Shaw, R (2006). Indian Ocean tsunami and aftermath: Need for environment-disaster synergy in the reconstruction process. Disaster Prevention and Management, 15(1), 5-20.

Shibata, Y (2012). Institutionalization and operation of special-EIA for recovery from the great east Japan earthquake. In Japan-UK Joint Seminar on Policy Integration Between Environmental Assessment and Disaster Management-Proceedings. http://www.nishikiz.depe.titech.ac.jp/JPUK2012/Proceedings_of_the_JP-UK_joint_WS.pdf.

Sidle, RC, WH Benson, JF Carriger and T Kamai (2013). Broader perspective on ecosystem sustainability: Consequences for decision making. Proceedings of the National Academy of Sciences of the United States of America (PNAS), 110(23), 9201-9208.

Smith, K (2013) Environmental Hazards: Assessing Risk and Reducing Disaster. Oxon: Routledge.

Spaling, H and B Vroom (2007). Environmental assessment after the 2004 tsunami: A case study, lessons and prospects. Impact Assessment and Project Appraisal, 25(1), 43-52.

Srinivas, H and Y Nakagawa (2008). Environmental implications for disaster preparedness: Lessons learnt from the Indian Ocean Tsunami. Journal of Environmental Management, 89(1), 4-13.

Steinberg, F (2007). Housing reconstruction and rehabilitation in Aceh and Nias, Indonesia - Rebuilding lives. Habitat International, 31(1), 150-166.

Swain, S and R Therivel (2012). Environmental impacts of civil emergency plans and of their exemption from SEA. In Japan-UK Joint Seminar on Policy Integration Between Environmental Assessment and Disaster Management-Proceedings. http://www.nishikiz.depe.titech.ac.jp/JPUK2012/Proceedings_of_the_JP-UK_joint_WS.pdf.

Tajima, R and TB Fischer (2013). Should different impact assessment instruments be integrated? Evidence from English spatial planning. Environmental Impact Assessment Review, 41, 29-37. 
Therivel, R and TB Fischer (2012). Sustainability appraisal in England. UVP Report, 26(1), 16-21.

Therivel, R and P Morris (2009). Introduction. In Methods of Environmental Impact Assessment. P Morris and R Therivel (eds.). Abingdon: Routledge, pp. 3-21.

United Nations Office for Disaster Risk Reduction (UNISDR) (2011). Hyogo Framework for Action 2005-2015. Building the Resilience of Nations and Communities to Disasters. Mid-Term Review 2010-2011. Geneva: UNISDR.

United Nations Office for Disaster Risk Reduction (UNISDR) (2013). Implementation of the Hyogo Framework for Action. Summary of Reports 2007-2013. Geneva: UNISDR.

United Nations Environmental Programme (UNEP) (2008). Environmental Needs Assessment in Post-Disaster Situations - A Practical Guide for Implementation. Geneva: UNEP.

Viljoen, MF, LA Du Plessis, HJ Booysen, HJ Weepener, M Braune, D van Bladeren and M Butler (2001). Flood damage management aid for integrated sustainable development planning in South Africa. WRC Report No. 889/1/01.

Wei, Y, Y Fan, C Lu and H Tsai (2004). The assessment of vulnerability to natural disasters in China by using the DEA method. Environmental Impact Assessment Review, 24(4), 427-439.

Wu, JY and MK Lindell (2004). Housing reconstruction after two major earthquakes: The 1994 northridge earthquake in the United States and the 1999 Chi-Chi earthquake in Taiwan. Disasters, 28(1), 63-81.

$\mathrm{Xu}, \mathrm{X}, \mathrm{Y}$ Tan and GS Yang (2013). Environmental impact assessments of the three gorges project in China: Issues and interventions. Earth-Science Reviews, 124, 115-125. 